\title{
13
}

\section{The Personal Social Services Today and Tomorrow}

The previous chapters have traced a path for the personal social services in England from the feast of funding in the early 1970s to the financial famine since 2010. This final Postscript reflects on this 50-year journey and looks forward to the future.

Unlike the rest of the book it is rather more free flow and free form, focusing on my perceptions rather than-as in previous chapters-an account largely informed by the recollections and interpretations of those who had key roles as events were unfolding.

\section{What to Celebrate}

One of the features of the past half century of the personal social services is how social workers have been in, or close to, the vanguard in driving positive and constructive change. They have often played this role in alliance with others. Here are five examples: 
1. It was social workers within the personal social services who were central to the closure of the large institutions. In the 1970s and 1980s it included the move away from residential nurseries for young children, the large approved schools for adolescents, and the big children's homes and children's cottage villages. In the 1980s and 1990s it included the closure and re-provisioning of services previously located in the large isolated county asylums, mental handicap hospitals, and the long-stay geriatric wards.

2. It was social workers who, with encouragement and campaigning from disabled people, moved away from a concept of the professional as distant patronising expert with closely protected knowledge to the professional social worker as an ally and enabler, recognising the strengths, capacity, competence and potential of others.

3. Before personalisation became a mainstream term and policy it was local authority social services who worked around restrictive legislation to make (in)direct cash payments available to disabled people, assisting them to have more choice and control.

4. It was social work, especially through its teachers and educators, which was aligned alongside others in the 1970s and 1980s in opening up the debate about discrimination and oppression in its varied forms.

5. The development within social work of strength-based models of practice and the commitment to exploring and reporting on their impact has re-shaped and strengthened social work. Strength-based models of practice do not remove the need for social workers to be intrigued and imaginative in their assessments and action planning, but they have the potential to promote and improve communication, engagement and partnership working with children and adults. There is a need, however, to avoid the danger that using the tools and techniques provided within the models becomes the goal rather than a means.

\section{What to Recall and Remember}

There are also traditions within social work which ought to be treasured and maintained, such as: 
1. The importance of teams and team work and of reflective supervision. It is difficult to identify other professions which from the 1970s and before had team work and reflective supervision so ingrained in their structures and practice.

2. The need to be political as well as person-focused as a part of social workers' professional role. This has been challenged throughout the past 50 years, and especially by ministers and their advisors during the 2010s, but social work is about seeing people in their broader context. This includes recognising and challenging how discrimination, disadvantage and deprivation damages and distorts lives, and collectively exposing its impact and campaigning for it to be addressed.

3. Social work is often on the margins of attention and is a minor concern of the public, press and politicians (except when it becomes the focus of blame for a tragedy). On its own it is not likely to have much leverage and impact in creating agendas and generating change. Alliances and partnerships have been a part of social workers' approach to delivering on the professional responsibility to be clear about answering Howard Becker's question 'Whose Side Are We On?'

4. Social work is intellectually as well as emotionally demanding. It requires the capability to make judgements and to plan action based on complex but always incomplete information. It is why social workers need to have critical appraisal skills and to be intelligent and imaginative. This should be supported by social work being a graduate profession with entry standards and qualifying courses which prioritise intelligence and academic ability as well as valuing life experience and the value-base of its entrants.

\section{What to Mourn}

1. How risk and rationing have come to trump relationships and rights as key components of social workers' practice. It has skewed how social workers spend their time and how they might be viewed by others, including those they might seek to help. Their work and time is often 
now more focused on monitoring and surveillance rather than being a resource to people at a time of crisis and creating and mobilising community resources.

2. How there is now an imbalance between professional space and discretion and proceduralised and bureaucratised practice. This is not an argument for unregulated and unseen practice with variations in competency and performance little recognised or addressed. It is an argument for recognising professional competence and creativity and having the confidence to let it blossom, and prioritising celebration and recognition over mistrust and monitoring.

3. How organisational structures and employment patterns of social workers have undermined the building of caring and trusting relationships with people, young and old, who are often in the midst of psychosocial crisis as a consequence of changing life circumstances because of illness, disability, relationship breakdown or abuse. Customer call centres and hand-overs between teams and social workers because of too much task specialisation is disruptive of relationships with service users. It also undermines knowing service users' history. In children's services, for example, work is moved between initial assessment, children in need, child protection, court proceedings, care and leaving care teams and workers, creating fragmentation and frustration. The pressure to close down work quickly to take on new work also challenges the opportunity to build knowledge of, and positive relationships with, those who social workers might seek to assist. None of this is helped by the relatively recent emergence of short-term agency social workers and managers.

4. The busyness which is squeezing out time for meaningful contact rather than monitoring between social workers and service users, and is also creating a less stable and less experienced workforce.

5. Divisive and too early specialisation within social worker's initial professional education. It restricts the breadth and blinkers the knowledge of social workers, which then limits assessment and understanding of complex lives and personal histories. The focus on creating too early specialisation and foreshortened education-now provided outside of universities and higher education and with funding from investment bankers-also restricts future life-long career choices and movement 
for social workers. It has taken the focus away from developing post-qualifying education, training and qualifications which is where specialisation should be developed and given recognition.

6. The blame culture which promotes defensive and bureaucratised practice and creates less confident organisations, managers and practitioners, and leads to low morale and workforce turnover and instability.

7. Hit-and-run inspectorates, and hit-and-run inquiries and reviews, where judgements are based on standards of near perfection and with all the benefits of hindsight. They take little account of the realities and complexities of social work which are not reduced by more procedures and more monitoring and auditing. They often choose to ignore and fail to comment on the limitations of resources and the impact of negative organisational cultures. They are experienced as brutal and bullying and generate threat and fear. They distort attention, and protecting from criticism from inspectors becomes for some agencies the organisation's overriding goal.

8. The increasing attempts to politically control and reposition social work from governments which are creating division within communities, promoting discrimination through their rhetoric and policies, and generating greater inequality and more extensive and intensive deprivation.

9. The priority given to privatising the personal social services with pursuit of profit trumping a commitment to public service. It adds costs, complexity and opaque accountability through the processes of setting, letting and monitoring contracts, with distant ownership, and it drives down standards in the search to reduce costs to generate profits.

\section{What to Expect}

1. Circumstances and communities will continue to change. Climate and political changes are likely to lead to more, not less, population movement. In the context of increasing nationalism and state isolationism the vilification and targeting of migrating and asylum-seeking 
people may intensify with intensifying punitive policies such as 'no access to public funds' and the continuing incarceration of asylumseekers. An increasing child and adult protection concern and category is likely to be trafficking, and the state itself may be complicit in abusing children by the response it gives to asylum-seeking families.

2. More government monitoring and oversight with dissent demonised. This is already happening with anti-terrorists activities and the Respect and Prevent agendas and procedures now capturing within the net those who are active with their concerns about the environment, nuclear weapons and animal welfare [1]. There is the danger that 'thought abuse' [2] becomes another child and vulnerable adults abuse category for children, young people and others engaged and active in expressing concerns, for example, about the environment.

3. A widening gap between rich and poor is a continuing frightful prospect after ten years of politically chosen austerity already having increased inequality and, even more damning, reduced the life expectancy and quality of life for poor children and adults $[3,4,5]$.

4. The opportunities of technology. As yet unpredictable whether what might be promised on the tin gets delivered, but the opportunities for technology to enhance independent living, quality of life, and smart working are still largely untapped, as are the advances in genome medicine with the possibility of extending life-spans but also, importantly, years of healthy and independent living.

5. A focus on housing, transport, communications and community infrastructures which enable people to live independently and when help is needed for this to be provided within inter-dependent communities rather than by separate, specialist and segregated services. This does not negate the role of social workers. It reinforces their community and resource development role. John Bolton-who had a professional background as a social worker which included community development - recalled when director of social services in Coventry:

CSCI sent me a letter saying 'This is your improvement agenda for the next year. I sent the letter back saying 'Thank you for your improvement agenda, this is mine'. And I said 'I'm not going to do some of these things'. I was not going to help more people to live at home'. Every year 
this upset CSCI. I said 'I'm going to help fewer people to live at home every year because I'm actually going to promote their independence'. It really annoyed them, but staff loved it because we had clarity about what we were doing and we were slightly putting a V sign up to the system which social workers liked. [John Bolton interview]

And two personal anecdotes from my time as social services director in Wiltshire. When a well past-its-sell-by-date local Leonard Cheshire care home out in the countryside was closing there were twelve residents who wanted to remain in our local area. There was district council owned sheltered accommodation in a town centre which was under-used. It was modernised and converted into housing where the care home residents could choose to move to as tenants and maintain their friendships but with independence. We thought we should attach a communal centre to the development, but instead the new tenants wanted the money spent under their direction to improve access to every-day universal facilities in the town-shops, cinema, swimming pool, sports ground, leisure centre and pubs-and with direct payments to assist them in using these community resources.

The second example was about the once or twice weekly luncheon clubs in village halls which the council's social services funded through grants which paid for the hire of the hall, payment of the cook, and taxi fares to bring older people to the luncheon clubs. Those attending paid about $£ 5$ per day. Attendance tailed off when the village pubs introduced on a couple of lunchtimes each week two course luncheons for people aged over 65 years for a similar price as the luncheon club meals. Older people chose the pub meals and ambience over the village hall luncheon clubs. It was a win-win for the older people and the community, which benefited from a pub which was more viable and vibrant throughout the week. The grants paid for the luncheon clubs were now made available as direct payments to cover the transport costs to the pubs. 


\section{What to Seek to Shape for the Future}

1. A return to a focus on relationships as a key component of social work, with continuity of contact with service users, and with space and time to engage with service users as was and is still being achieved, for example, in family centres and mental health resource centres. As Brid Featherstone, Sue White and Kate Morris argued in 2014:

We need change because, over the past few decades, a transactional form of welfare developed. This model is rooted in market reforms with their embrace of centralised bureaucracy, targets and timescales, and emphasises efficiency and a particular limited form of accountability. Yet, time and time again, what service users value and indeed what the research tells us is needed for a good society is something more human, caring and time rich ... We need change because we have lost sight of what is needed in a good society for its families to flourish. [6]

2. A focus on communities as a lived experience, and potential resource for service users, and with knowledge of communities as a part of understanding the context of people's lives. Locating and embedding the personal social services and social workers within communities is likely to increase their accessibility and acceptability and also their relevance as a local resource.

3. Promoting organisational and workforce continuity and stability over churn and change. Too frequent, too rapid, and too expansive change leads to disruption and disjunction and is also distracting. It also often is never allowed to bed in and fails to deliver what was intended. Churn and change not only disrupts the workforce and relationships with service users, but it also undermines partnership working and trust with other agencies and workers.

4. An understanding that terrible events and tragedies will happen and that these are not necessarily the consequence of 'failings' by workers or organisations. It is not possible to predict or have perfect control over the future. Judgements have to be made at the time in the context of workloads and work pressures, based on incomplete and changing 
information, and without a perfect crystal ball. Learning cultures recognise and accept terrible events as an opportunity to reflect and learn. Blame cultures look to allocate accountability which is seen as equivalent to guilt. It is destructive and undermining of learning and development and measured judgements.

5. Professional commitment and strength to champion social work and its contribution and to build alliances with others to confront and challenge discrimination and oppression. As the personal social services in England and across the UK are largely shaped by statute and delivered as a state responsibility individual opportunity and capacity to challenge is inevitably limited by being an agency employee. All the more important for social workers and others to create collective voices locally, regionally and nationally so that they are not isolated and vulnerable. Use those collective voices through local and national media to challenge the narratives about poverty being the consequence of personal fecklessness and recklessness, impairment and illness as personal failings and weakness, and public services and public servants as sluggish and self-interested.

And what of the Seebohm Committee and its aspirations 50 years ago? David Behan reflected:

Seebohm was a solution to those issues which were identified by that first generation after the Second World War. My personal view is that we never saw the Seebohm departments delivered. [What we saw] was Seebohm without prevention. I began my career in 1974 and the investment in the 1970s got close to the preventative element of Seebohm, but when the economics began to bite in the 1980s I think that effectively finished the delivery of the vision that was Seebohm. My judgement of the underpinning philosophy of Seebohm was that it was absolutely first class and excellent, but the issue was to support the ambition of the idea through to delivery ... the economics, the social philosophy, the politics and the morality at the time was needed and you don't always get those alignments. [David Behan interview]

And what about social work and its future? David Jones commented: 
I have never ever bought into the view that social work is as vulnerable as some people like to make it because it is such an essential service, and when it hits the fan people need social workers. I have always felt reasonably confident about that. I don't buy into "we are going to be wiped out." [David Jones interview]

Recent years have shown how uncertain and unpredictable what 'hits the fan' can be, from man-made disasters (such as the 2008 banking crisis and wars with displaced populations) and natural disasters (such earthquakes, volcanic eruptions and tsunamis) to disasters which are a culmination of human and natural activity (such as the climate change consequences of droughts, famines and widespread fires).

Most recently the coronavirus pandemic has not only shown the varying competence of governments but also brought to the fore who are the real 'key workers' when there is a crisis across communities-they are largely public sector workers and those in the private sector in the lowpaid insecure gig economy. Alongside health workers, those working in social care and social workers have, rather belatedly, received public and then political recognition for the crucial work they undertake, but alongside the terrible cost of older people in care homes left stranded when they might have received treatment in hospitals when critically ill and vulnerable children and others left largely unseen at home. The danger is that it will be back to 'business as usual' once the pandemic is under control and the economy, growth and increasing affluence for a minority once again become the priority and the c-virus key workers are returned to their low and marginalised status.

There will, however, always be people needing help in the midst of personal and community crisis. There will always be major life-changing traumas and events where others can help to create space, safety and calm amongst chaos and turmoil and to help see and think through a way forward. There will be those who are vulnerable and victimised needing allies and advocates. And there is continuing social change to be shaped which would benefit from the values, knowledge and commitment of social workers. 